\title{
Caracterización molecular de péptidos antimicrobianos a partir de muestras de piel de Agalychnis spurrelli (Anura: Hylidae)
}

\author{
Andrea P. Vargas ${ }^{1}$, Óscar Pérez ${ }^{2}$, David Ortega - Paredes ${ }^{2}$, Myrian Rivera $^{1}$ \\ ${ }^{1}$ Laboratorio de Investigaciones de Citogenética y Biomoléculas de Anfibios (LICBA), \\ Pontificia Universidad Católica del Ecuador, Quito, Ecuador. \\ ${ }^{2}$ Laboratorio de Biología del Desarrollo, Escuela de Ciencias Biológicas, \\ Pontificia Universidad Católica del Ecuador,, Quito, Ecuador. ap.vargash@gmail.com
}

Recibido: 2015-08-03; aceptado: 2015-08-27

\begin{abstract}
RESUMEN.- Las secreciones de la piel de Agalychnis spurrelli han probado tener una marcada actividad antimicrobiana sobre diferentes microrganismos patógenos por la presencia de biomoléculas en ellas. Se realizaron análisis moleculares del ARN mensajero de la piel de A. spurrelli para determinar el tipo de péptido antimicrobiano presente en las secreciones cutáneas de esta especie. Para amplificar las secuencias precursoras de los péptidos maduros, se utilizaron iniciadores específicos que contienen secuencias altamente conservadas. Como resultado se obtuvo una secuencia de ADN complementario de $357 \mathrm{pb}$, la cual fue comparada con sus ortólogos de otras especies de la misma subfamilia Phyllomedusinae, se lograron índices de identidad muy altos para precursores de dermaseptinas. Finalmente, para el análisis de la secuencia de $\mathrm{ADN}$ complementario, se tradujo la secuencia nucleotídica por codones, con lo que se obtuvo una secuencia aminoacídica. Dicha secuencia posee las características particulares de péptidos de la familia de las dermaseptinas: una secuencia altamente conservada, una propieza acídica con los aminoácidos Lisina y Arginina y el extremo C-terminal variable. En conclusión, la secreción total de Agalychnis spurrelli contiene un péptido de la familia de las dermaseptinas o un péptido relacionado con ellas.
\end{abstract}

PALABRAS CLAVES: ADN complementario, Dermaseptinas, Phyllomedusinae, secuencias precursoras

ABSTRACT.- The skin secretions of Agalychnis spurrelli have proven to have a strong antimicrobial activity on different pathogens because they contain certain biomolecules that have antimicrobial action. In the Phyllomedusinae family antimicrobial peptides are commonly present. Molecular analysis where performed in mRNA from the skin of A. spurrelli to determine the type of antimicrobial peptide present in the skin secretions of this species. The precursor that amplifies the sequences of mature peptides, where amplified by using specific primers that contained the highly conserved sequence, characteristic in this family. The result was a sequence of DNA complementary of $357 \mathrm{pb}$. This sequence was compared with their orthologs from other species of the same subfamily Phyllomedusinae, obtaining very high levels of identity for dermaseptin precursors. Finally, for the analysis of complementary DNA sequence, this was translated into an amino acid sequence. This sequence has the characteristics of peptides of the dermaseptin family: a highly conserved sequence, an acidic propiece with Lysine and Arginine and the variable the C-terminus. In conclusion, the total secretions of Agalychnis spurrelli contain a peptide of the family of dermaseptin or a dermaseptin like peptide.

KEYWORDS: complementary DNA, Dermaseptins, Phyllomedusinae, precursor sequences,.

\section{INTRODUCCIÓN}

Por la cantidad de especies descritas a nivel mundial, Ecuador está catalogado como el tercer país en diversidad de anfibios, y el primero en el mundo por el número de especies por área (Coloma et al., 2011). En el pasado, las comunidades locales han utilizado muchas de estas especies con fines medicinales y terapéuticos. Las biomoléculas secretadas en la piel de los anfibios constituyen una fuente biológica de compuestos con varias funciones fisiológicas, especialmente de defensa (Barra y Simmaco, 1995), dirigida hacia patógenos externos. Estas moléculas forman parte de la inmunidad innata de estos organismos y pueden ser aminas biogénicas, alcaloides complejos y 
péptidos antimicrobianos (Simmaco et al., 1998). Para que la inmunidad innata, pueda actuar sobre patógenos que evolucionan rápidamente, los genes del sistema inmune de los anfibios poseen niveles muy altos de polimorfismos, dados por la presión selectiva. Este polimorfismo está asociado con la actividad antimicrobiana dada por los genes implicados. Ranas que pertenecen al mismo género pero de diferentes especies o subfamilias, pueden tener diferentes tipos de péptidos con diferente tamaño, carga, hidrofobicidad, conformación y espectro de acción (Duda et al., 2002).

En los anfibios ecuatorianos la familia Hylidae es una de las más extensas por contener alrededor de 51 géneros incluidos en tres subfamilias: Hylinae, Pelodryadinae y Phyllomedusinae. De la subfamilia Phyllomedusinae han podido ser aislados aproximadamente 80 péptidos antimicrobianos que, agrupados por alineamiento múltiple de sus secuencias, forman 7 familias de péptidos: las phylloseptinas (PLS), las dermatoxinas (DRT), las plasticinas (PTC), las phyllotoxinas (PLX), las hyposinas (HPS), los péptidos huérfanos y las dermaseptinas (DRS) (Amiche et al., 2008).

Las Dermaseptinas están representadas por 50 péptidos provenientes de los géneros Pachymedusa, Phyllomedusa y Agalychnis (Amiche et al., 2008). Son lineares, catiónicos y generalmente no hemolíticos (De Lucca et al., 1998). La naturaleza anfipática de las dermaseptinas les permite una interacción con la membrana del patógeno causando un colapso total de la integridad de la misma, dando como resultado la pérdida de la permeabilidad (Charpentier et al., 1998).

Para la mayoría de las dermaseptinas los precursores codifican una sola copia del péptido antimicrobiano maduro al extremo C-terminal de la secuencia. Una comparación de las secuencias precursoras de los péptidos revela que poseen una preproregión $\mathrm{N}$-terminal común, altamente conservada inter e intraespecíficamente y una región C-terminal diferente que corresponde a los péptidos antimicrobianos maduros. $\mathrm{La}$ preprorregión conservada comprende una señal peptídica hidrofóbica de 22 residuos seguidos por una propieza acídica que termina en una prohormona que procesa la señal Lisina Arginina (Lys-Arg) (Duda et al., 2002).

Por lo antes expuesto, en la presente investigación se realizaron análisis moleculares del ARN mensajero de la piel de Agalychnis spurrelli para determinar la presencia de un péptido antimicrobiano en las secreciones cutáneas de esta especie, las mismas que han probado tener una amplia actividad antimicrobiana (Cilveti et al., 2013), antifúngica (Vargas, 2012) y anticancerígena (Chuang, 2012).

\section{MATERIALES Y MÉTODOS}

Para la caracterización con métodos moleculares de péptidos antimicrobianos se siguió el protocolo determinado por Vanhoye y colaboradores (2003). Tres especímenes (SC26539, SC26542 y SC26543) fueron sacrificados colocándoles Lidocaina en el área bucal para evitar dañar la piel. Posteriormente se procedió a removerla para obtener varias muestras de aproximadamente $180 \mathrm{mg}$ que fueron conservadas y almacenadas en RNAlater (QIAGEN Cat.No. 76106) a $-20^{\circ} \mathrm{C}$ según lo especifica el protocolo de clonación de Vanhoye et al. (2003). Consecutivamente se extrajo el ARN total. Se utilizó el reactivo Tri Reagent (MOLECULAR RESEARCH CENTER INC. Cat. No. TR-118), el protocolo se siguió según las especificaciones del fabricante mediante la centrífuga Refrigerated Centrifuge SIGMA 1-15K. El ARN resultante se disolvió en 25 $\mu l$ de agua DEPC. Para comprobar la presencia de ácidos nucleicos se corrió el ARN extraído en geles de agarosa al $1 \%$ y TBE $0.5 \mathrm{X}$.

Después, el ADN complementario (ADNc) fue sintetizado a partir del ARN total extraído de las muestras de piel. Para esto se utilizó la transcriptasa reversa M-MulV (ROCHE Cat .No.11062603001) así como el protocolo especificado por el fabricante con los siguientes reactivos: $5 \mu$ de buffer de incubación 5X, $1.25 \mu \mathrm{l}$ de M-MulV transcriptasa reversa, $2.5 \mu \mathrm{l}$ de PolyA oligodT (ROCHE Cat. No. 10108677001), $1 \mu \mathrm{l}$ de Inhibidor de RNAsas (ROCHE Cat. No. 03335399001), $1.25 \mu$ de deoxinucleotidos trifosfato (dNTPs) (INVITROGEN Cat. No. 1842701), $5 \mu \mathrm{de}$ templado de ARN total $(2-5 \mu \mathrm{g})$ y $9 \mu \mathrm{l}$ de agua libre de nucleasas (DEPC).

$\mathrm{Al}$ producto de la reacción se lo colocó en un tubo de microcentrífuga de $1.5 \mathrm{ml}$ con un volumen final de $25 \mu \mathrm{l}$ y posteriormente fue incubado en un baño María Reciprocal Shaking "Bath PRECISION", por una hora a una temperatura de $37^{\circ} \mathrm{C}$. A partir del ADNc sintetizado se realizó un protocolo de reacción en cadena de la polimerasa (PCR), con el objetivo de amplificar una porción de la secuencia del precursor del péptido de A. spurrelli del ADN complementario total obtenido.

Para realizar la amplificación se diseñaron iniciadores específicos basándose en secuencias conocidas de precursores de dermaseptinas encontrados en especies cercanas a $A$. spurrelli como Agalychnis callidryas y Agalychnis annae. Para esto, dos secuencias de precursores de $A$. callidryas y una de $A$. annae fueron alineadas entre sí. Dichas secuencias fueron alineadas mediante el programa ClustalW de European Bioinformatics Institute EMBL. Una vez encontradas las porciones 
más alineadas se utilizó el programa BCM Searchlauncher de Baylor Collage of Medicine HGSC para diseñar los iniciadores corriente abajo A.spuR1 y A.spuR2, los cuales fueron iniciadores degenerados. (Tabla 1)

El iniciador corriente arriba A.spuF1 pertenece a la secuencia nucleotídica que codifica para el extremo N-terminal de la preprorregión de los precursores de dermaseptina diseñado por Vanhoye et al. (2003). La síntesis de los iniciadores fue realizada bajo pedido por INVITROGEN. Una vez obtenidos los iniciadores A.spuF1, A.spuR1 y A.spuR2 se realizó un PCR anidado. Este procedimiento utilizó una ADN polimerasa GoTaq (PROMEGA Cat. No. M3005) siguiendo el protocolo recomendado por el fabricante.

Para la elaboración de estas amplificaciones se utilizó una termocicladora PTC-100 MJ RESEARCH. La reacción se colocó en la termocicladora, la cual se programó con los siguientes ciclos: desnaturalización inicial a $94^{\circ} \mathrm{C}$ por 2 minutos, acoplamiento a $56^{\circ} \mathrm{C}$ (temperatura dependiente de la secuencia de los iniciadores empleados) por un minuto, extensión a $72^{\circ} \mathrm{C}$ por 3 minutos con 30 segundos y extensión final a $72^{\circ} \mathrm{C}$ por 5 minutos. Los ciclos 2, 3 y 4 se repitieron por 33 veces según las recomendaciones del fabricante de la polimerasa. La temperatura de acoplamiento se obtuvo mediante la ecuación de Wallace. Al término del PCR todas las muestras resultantes fueron corridas en geles de agarosa y visualizadas. Las bandas del tamaño adecuado fueron extraídas del gel de agarosa para realizar la Amplificación Rápida De Extremos 3' De ADN Complementario (3'RACE). Se realizó el 3'RACE usando la cola de poliA presente en el ARN como sitio de inicio para PCR. Para este procedimiento se utilizó el ARN total extraído de la piel de la rana empleando como iniciadores específicos al iniciador corriente arriba A.spuF1 basado en el dominio altamente conservado del extremo N-terminal de los péptidos antimicrobianos de la familia Hylidae. Los iniciadores específicos corriente abajo AP y AUAP fueron obtenidos del Kit de reacción del 3'RACE (System for Rapid Amplification of cDNA Ends INIVTROGEN Cat. No. 18373-019).

Para la síntesis de ADN complementario se procedió según las especificaciones del fabricante utilizando de 1 a $5 \mu \mathrm{l}$ del ARN total extraído de la piel de $A$. spurrelli y un ARN control incluido, en el Kit.

Para la amplificación del ADNc de interés se siguieron las especificaciones del Kit (3'RACE System for Rapid Amplification of cDNA Ends INVITROGEN Cat. No. 18373-019).

La termocicladora fue programada con los siguientes ciclos: Desnaturalización inicial a $94^{\circ} \mathrm{C}$ por 3 minutos, desnaturalización a $94^{\circ} \mathrm{C}$ por un minuto, acoplamiento a $56^{\circ} \mathrm{C}$ por un minuto, extensión a $72^{\circ} \mathrm{C}$ por 3 minutos con 30 segundos y extensión final a $72^{\circ} \mathrm{C}$ por 5 minutos. Los ciclos 2 , 3 y 4 se repitieron por 35 veces según las recomendaciones del fabricante de la GoTaq polimerasa y el protocolo de 3’RACE. Luego de la amplificación se extrajo la muestra con $50 \mu \mathrm{l}$ de cloroformo y se transfirió la fase acuosa en un tubo nuevo.

Al término del PCR, todas las muestras resultantes fueron corridas en geles de agarosa y visualizadas, las bandas del tamaño adecuado fueron extraídas del gel.

Tabla 1. Iniciadores utilizados en la caracterización de péptidos antimicrobianos de la piel de $A$. spurrelli. De arriba hacia abajo: Tres iniciadores degenerados diseñados a partir de secuencias conocidas de precursores de péptidos antimicrobianos; tres iniciadores en el Kit de 3' RACE AP, AUP, AUAP; y tres iniciadores incluidos en el Kit de clonación pCR 2.1 TOPO M13 Reverse, M13 Forward y T7 Promoter.

\begin{tabular}{|c|c|c|}
\hline Primers & Secuencia & Referencia \\
\hline Primer degenerado A.spuF1 & 5'-GGC TTT CCT KAA GAA ATC TC-3' & \\
\hline Primer degenerado A.spuR1 & 5'-CСТ CYТ САТ СТТ САТ ТTТ СТС-3' & \\
\hline Primer degenerado A.spuR2 & 5'-CAC TTT GCT CRT CRT CTT CTT G-3' & \\
\hline 3' RACE Adapter Primer & $\begin{array}{c}\text { 5'-GGC CAC GCG TCG ACT AGT ACT TTT } \\
\text { TTT TTT TTT TTT T-3' }\end{array}$ & AP primer INVITROGEN \\
\hline 3’RACE Universal Amplification Primer & $\begin{array}{c}\text { 5'-CAU CAU CAU CAU GAC CGT TCA } \\
\text { GCT GGA TAT TAC-3' }\end{array}$ & UAP primer INVITROGEN \\
\hline $\begin{array}{l}\text { 3' RACE Abridged Universal } \\
\text { Amplification Primer }\end{array}$ & 5'-GGC CAC GCG TCG ACT AGT AC-3' & AUAP primer INVITROGEN \\
\hline M13 Reverse Primer & $\begin{array}{c}\text { 5'-CAG GAA ACA GCT ATC AC GTC CTT } \\
\text { TGT CGA TAC TG-3' }\end{array}$ & pCR 2.1 TOPO \\
\hline T7 Promoter & $\begin{array}{c}\text { 5'-AGT GAG TGC TAT TA TCA CTC AGC } \\
\text { ATA AT-3' }\end{array}$ & pCR 2.1 TOPO \\
\hline M13 Forward(-20)Primer & $\begin{array}{c}\text { 3'-CTG GCC GTC GTT TTA C GAC CGG } \\
\text { CAG CAA AAT G-5' }\end{array}$ & pCR 2.1 TOPO \\
\hline
\end{tabular}


Los fragmentos de A.spuF1-A.spuR1, A.spuF1-A. spuR2 y A.spuF1-AUAP (3'RACE) se ligaron al vector pGEM ${ }^{\circ}-\mathrm{T}$ Vector System (PROMEGA Cat. No. A3610), por poseer una región de resistencia a la ampicilina y alfa complementación. El protocolo fue realizado según las especificaciones del fabricante. Las bacterias competentes se transformaron con los vectores que contenían los fragmentos A.spuF1-A.spuR1, A.spuF1-A.spuR2 y 3'RACE. Para esta transformación se utilizaron las bacterias químicamente competentes One ShotR TOP10 Competent Cells INVITROGEN (Cat. No. C40401). El protocolo se realizó según las especificaciones del fabricante. Simultáneamente a este protocolo se preparó el medio de cultivo bacteriano. Para esto se usó el medio Luria-Bertoni (LB) y Agar en 2 cajas Petri plásticas para cada fragmento. Una vez polimerizado el medio, se sembraron $30 \mu \mathrm{l}$ de X-Gal INVITROGEN (Cat. No. 15520018) a un concentración de $40 \mathrm{mg} / \mathrm{ml}$, y 15 $\mu \mathrm{l}$ de ampicilina ROCHE (Cat. No. 10835242001) a una concentración de $50 \mathrm{mg} / \mathrm{ml}$ para cada placa.

Posteriormente a su transformación, las bacterias fueron sembradas en el medio de cultivo previamente preparado. Pasadas las 24 horas se observó el crecimiento de colonias, y se marcó con un círculo a las colonias recombinadas con cada amplicón. Con el objetivo de conocer si las colonias crecidas en las cajas Petri contenían el inserto, se realizó un PCR de cada cultivo de colonias, mediante iniciadores específicos del vector A.spuF1-A.spuR1, A.spuF1-A.spuR2 y A. spuF1-AUAP ( $3^{\prime}$ RACE), con su respectiva temperatura de acoplamiento. Se escogieron tres colonias de A.spuF1-A.spuR1, A.spuF1-A.spuR2 y 3'RACE. A continuación se purificó el plásmido con el inserto de las colonias escogidas. Para este procedimiento se utilizó el kit High Pure Plasmid Isolation para preparaciones mini (ROCHE Cat. No. 11754777001). El Kit fue utilizado según las especificaciones del fabricante. Las muestras se enviaron a secuenciar con los iniciadores T7 corriente arriba y SP6 corriente abajo, específicos del vector. Las muestras fueron secuenciadas por el servicio de secuenciación MACROGEN Inc.

Para un análisis más profundo se realizóla traducción de las secuencias nucleotídicas empleando el programa BCM Search launcher de Baylor Collage of Medicine HGSC. Se obtuvieron 6 marcos de lectura, tres en sentido $5^{\prime} 3^{\prime}$ y tres en sentido $3^{\prime} 5^{\prime}$. Cada secuencia obtenida fue alineada con las secuencias aminoácidicas de péptidos antimicrobianos y de las especies más cercanas, seleccionando la secuencia mejor alineada usando el programa ClustalW del European Bioinformatics Institute EMBL, que indicó el índice de identidad entre ellas.

\section{RESULTADOS}

Como resultado de la amplificación del ADN complementario de $A$. spurrelli con los iniciadores específicos diseñados a partir de secuencias conocidas de precursores peptídicos, se obtuvo un gel de agarosa con varias bandas. Se pudieron observar dos bandas de aproximadamente 100 y 120 pb amplificada con los iniciadores A.spuF1-A.spuR1 y A.spuF1-A.spuR2. También se observó una banda de 357 pb aproximadamente, correspondiente a la amplificación de la secuencia total de interés, obtenida del 3'RACE con los iniciadores A. spuF1-AUAP (3’RACE). (Figura 1).

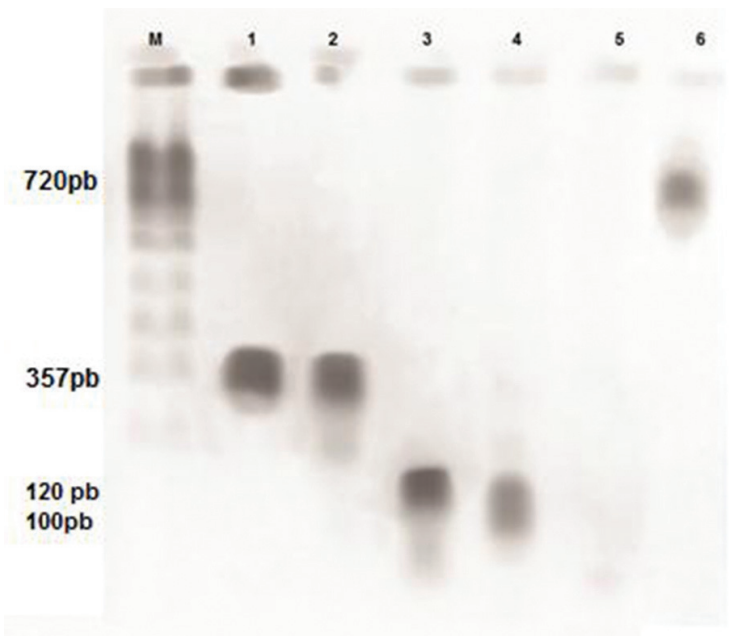

Figura 1. Amplicones A.spuF1 con A.spuR1, A.spuR2 y AUAP (3'RACE). De izquierda a derecha se puede observar: M, la escalera de peso molecular (Ladder); 1 y 2, secuencias de 357pb precursoras de dermaseptinas producto de 3'RACE; 3, amplicón de 120pb obtenido del PCR anidado con A.spuF1 y A.spuR1; 4, amplicón de 100pb obtenido del PCR anidado con A.spuF1 y A.spuR2; 5, control negativo; 6, control positivo (3'RACE).

De la clonación de las secuencias A.spuF1-A.spuR1, A.spuF1-A.spuR2 y A.spuF1-UAP (3'RACE) en bacterias competentes, se obtuvieron varias colonias transformadas con el inserto en la placa de cultivo. A continuación se seleccionó una colonia para realizar una amplificación con los iniciadores A. spuF1 y AUAP. Como resultado, en el gel de agarosa al $1 \%$, pudieron observarse bandas de 357 pb aproximadamente, que corresponden al tamaño esperado de la secuencia total del precursor de los péptidos antimicrobianos. Se realizó el mismo procedimiento con A.spuF1-A.spuR1 y A.spuF1-A.spuR2. Finalmente se seleccionaron tres colonias de cada inserto para ser purificadas y posteriormente secuenciadas. Como resultado de la purificación del plásmido y su posterior secuenciación se obtuvo la secuencia precursora del péptido de Agalychnis spurrelli que cuenta con 357 pb (Figura 2) y dos amplicones más pequeños que pertenecían a la amplificación de segmentos de la secuencia precursora de 100 y 120 pb. 


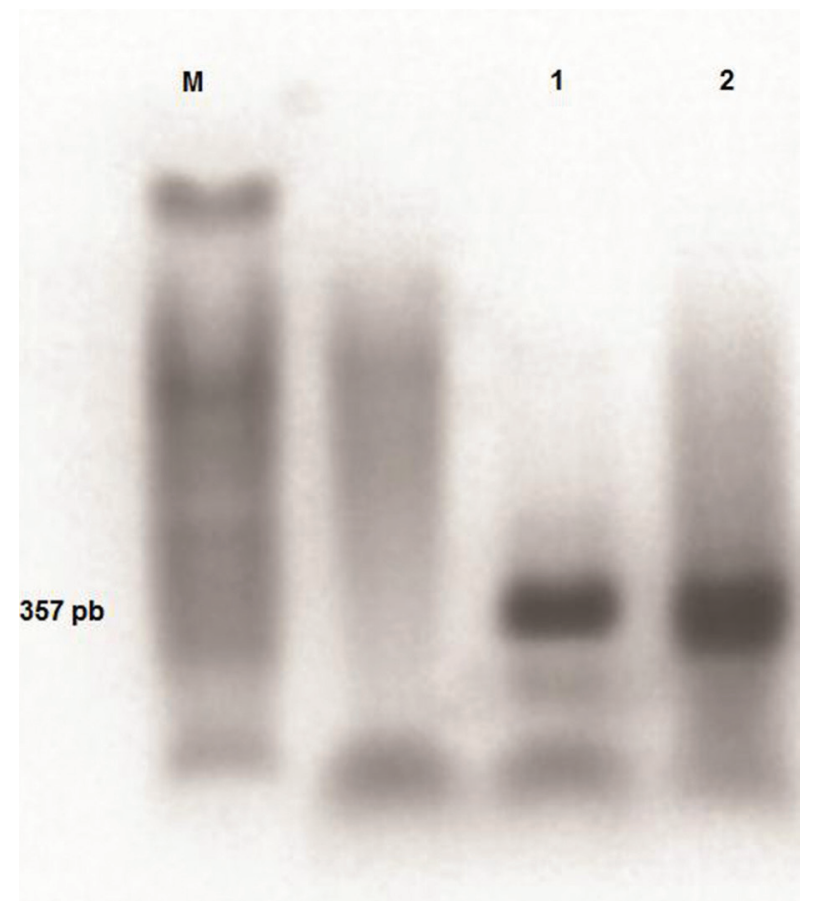

Figura 2. Amplicón de A.spuF1-AUAP a partir de colonias transformadas. Los amplicones de ADN fueron obtenidos a partir de la amplificación de colonias recombinadas, amplificadas con iniciadores A.spuF1-AUAP. De izquierda a derecha se observan la escalera de peso molecular seguida de las bandas uno y dos de $357 \mathrm{pb}$.

A continuación se procedió a comparar la secuencia precursora total de péptidos antimicrobianos de $A$. spurrelli con secuencias del banco genético National Center of Biotechnology Information (NCBI). Los índices de identidad obtenidos muestran que la secuencia precursora del péptido de Agalychnis spurrelli se encuentra estrechamente relacionada con secuencias precursoras de dermaseptinas y péptidos relacionados con dermaseptinas, aisladas de las especies Agalychnis annae, Agalychnis callydrias, Phyllomedusa sauvagei y Phyllomedusa hypochondrialis. (Tabla 2).

\section{DISCUSIÓN}

El ADN contiene empacada toda la información genética que un organismo necesita para desarrollarse y funcionar, y en base a esa información este puede construir proteínas (Watson et al., 2007). El ARN mensajero contiene la información genética procedente del ADN para la síntesis de proteínas. Estas a su vez son los productos finales de la mayoría de rutas de información y tienen que ser sintetizadas y transportadas en respuesta a las necesidades celulares del momento (Lehninger et al., 2008).

La información de los precursores de péptidos antimicrobianos presentes en la piel de los anfibios, está codificada en el ADN de cada una de las células del organismo. Sin embargo, estas secuencias son traducidas exclusivamente en las células de la piel para la producción de sustancias de defensa secretadas por las glándulas granulares (Tennessen y Blouin, 2008). Las secuencias de estos péptidos son muy similares entre especies relacionadas. (Figura 3).

Los anfibios de la familia Hylidae poseen precursores llamados preprodermaseptinas (Vanhoye et al., 2003) a partir de las cuales fueron diseñados los iniciadores A.spuF1 corriente arriba, A.spuR1 y A.spuR2 corriente abajo. Es posible encontrar ciertos segmentos de la secuencia de una proteína en organismos de un grupo taxonómico y no en otros grupos y estos segmentos pueden usarse como "secuencia firma" del grupo en el cual se encuentren (Lehninger et al., 2008).

Tabla 2. Índices de identidad de la secuencia A.spuF1-AUAP (3'RACE) de Agalychnis spurrelli comparados con las secuencias de sus ortólogos en otras especies.

\begin{tabular}{ccc}
\hline ESPECIE & TIPO DE SECUENCIA & IDENTIDAD MÁXIMA \\
\hline Agalychnis annae & mRNA for dermaseptine related peptide, clone AA 3-1 & $96 \%$ \\
Agalychnis callidryas & mRNA for DRP-AC1 precursor (drp.AC1 gene) & $89 \%$ \\
Phyllomedusa hypocondralis & mRNA for dermaseptine H2 protein precursor (dsn-2 gene) & $87 \%$ \\
Phyllomedusa hypocondralis & mRNA for dermaseptine H1 protein precursor (dsn-1 gene) & $87 \%$ \\
Agalychnis callidryas & Dermaseptien like precursor DRP-AC-3 mRNA & $90 \%$ \\
Phyllomedusa sauvagei & mRNA for preprodermaseptine S13 (drsS13 gene) & $83 \%$ \\
Phyllomedusa sauvagei & Partial mRNA for preprodermaseptine S12 (drs12 gene) & $83 \%$ \\
Phyllomedusa sauvagei & mRNA for dermaseptin sVII & $86 \%$ \\
Agalychnis annae & mRNA for dermaseptin-related peptide, clone AA-3-6 & $81 \%$ \\
Phyllomedusa hypocondralis & mRNA for preprodermaseptine H3 (dpp-H3 gene) & $89 \%$ \\
Agalychnis callidryas & mRNA for ARP-AC1 precursor & $80 \%$ \\
Phyllomedusa hypocondralis & mRNA for preprodermaseptine H4 & $91 \%$ \\
Phyllomedusa sauvagei & mRNA preprodermaseptine S11 (drsS11 gene) & $79 \%$ \\
\hline
\end{tabular}



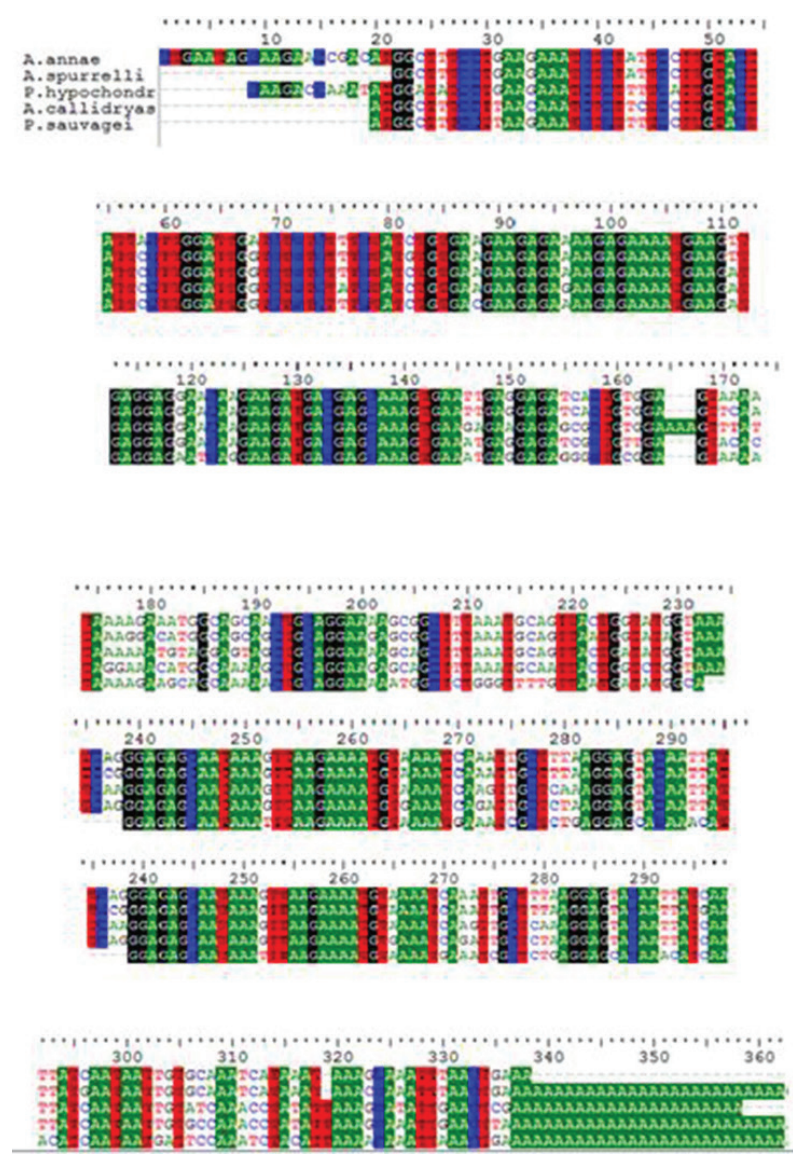

Figura 3. Alineamiento de secuencias precursoras de péptidos antimicrobianos de especies de la subfamilia Phyllomedusinae. Identidades nucleotídicas coloreadas, alineadas con el editor de alineamientos Bioedit.

La amplificación de una porción pequeña del precursor a partir de estos iniciadores indica que el dominio altamente conservado de péptidos antimicrobianos de la familia Hylidae, está presente en el mensajero de A. spurrelli. El alto grado de conservación de estas preprorregiones se debe a que se originó de una familia de multigenes pertenecientea unancestrocomún(Dudaetal.,2002). Sin embargo, a pesar de tener una preprorregión altamente conservada evolutivamente, los péptidos antimicrobianos poseen un extremo C-terminal muy variable. Esta variabilidad da como resultado una gran cantidad de péptidos de diferentes tamaños, secuencias y espectro antimicrobiológico (Vanhoye et al., 2003); no obstante, muchas de estas sustituciones de aminoácidos observadas en una familia de proteínas pueden ser de tipo conservador, es decir, sustituciones en las cuales un residuo de un aminoácido está remplazado por otro que posee propiedades químicas similares (Lehninger et al., 2008).

Para conocer el tamaño y la secuencia total del precursor del péptido antimicrobiano de A. spurrelli se realizó la técnica molecular llamada $3^{\prime}$ RACE (Rapid Amplification of cDNA Ends).

Esta técnica amplifica secuencias nucleotídicas a partir de un ARN mensajero usado como templado. El 3’RACE necesita dos secuencias iniciadoras específicas que encierren a la secuencia de interés y toma ventaja de la cola de poliA contenida en al ARNm como iniciador genérico para sintetizar ADN complementario (Sambrook y Russell, 2001). En el caso de A. spurrelli se tomó como iniciadores a la preprorregión altamente conservada con el iniciador A.spuF1 específico y el iniciador AUAP genérico que se une a la región conocida en el extremo 5' (Figura 4). Como resultado se obtuvo una secuencia de $357 \mathrm{pb}$, consistente con la longitud de los precursores de péptidos antimicrobianos de la familia Hylidae (Vanhoye et al., 2003).

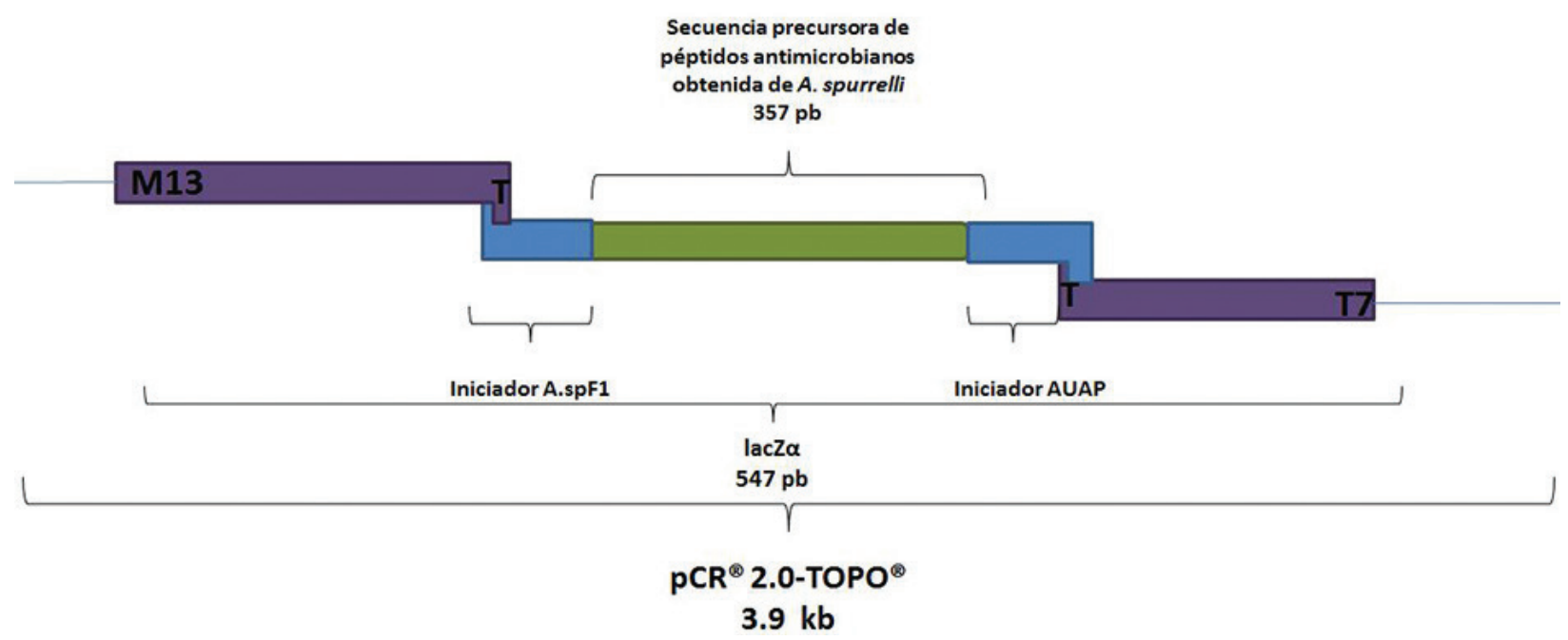

Figura 4. Esquema de la región amplificada y clonada usando métodos moleculares. En azul se observan la prepro-región altamente conservada de precursores de péptidos antimicrobianos usada como iniciador corriente arriba (A.spF1) y el iniciador de amplificación universal AUAP corriente abajo. En verde se observa la secuencia amplificada del precursor de péptidos antimicrobianos de $A$. spurrelli con 357 pares de base. Este fragmento y sus iniciadores se encuentran en el dominio lacZ- (3.9 kb) del vector de clonación pCR 2.0-TOPO. 
El alto índice de identidad que se obtuvo mediante la comparación y alineamiento de la secuencia resultante, con las secuencias precursoras de péptidos antimicrobianos presentes en el Banco Génico, NCBI, demostró que el extracto crudo de A. spurrelli contiene una dermaseptina o un péptido relacionado con las dermaseptinas. Se puede asegurar que se trata de una dermaseptina, por el alto grado de similitud de secuencias ortólogas con otras especies de la familia Hylidae como Agalychnis annae (mRNA for dermaseptin-related peptide, clone AA-3-1) con 96\%, Agalychnis callidryas (mRNA for DRP-AC1 precursor (drp-AC1 gene) con $89 \%$, Phyllomedusa hypochondrialis (mRNA for dermaseptin $\mathrm{H} 1$ y $\mathrm{H} 2$ protein precursor) con $87 \%$ y Phyllomedusa sauvagei (mRNA for preprodermaseptin S 12 y S13) con un $83 \%$ de similitud (Tabla 3 ).

Posterior al análisis de las secuencias de ADN complementario se procedió a traducir las secuencias aminoacídicas, se obtuvo como resultado seis marcos de lectura, los cuales fueron alineados con secuencias ortólogas presentes en el Banco Génico NCBI. Todos los marcos de lectura tuvieron índices de identidad altos. Esto podría indicar una estrecha relación en el origen de los péptidos antimicrobianos o incluso un origen común de los mismos. El marco de lectura 3'5' Frame 1, obtuvo la similaridad más alta con Agalychnis annae con un $90 \%$. Mientras que con las otras especies antes mencionada fluctúa entre $86 \%$ y $46 \%$, lo cual podría suponer una estrecha relación en el origen de los péptidos antimicrobianos de ambas especies (Figura 5).

Adicionalmente, la secuencia aminoacídica de $A$. spurrrelli presenta la región altamente conservada
3'5' Marco de lectura 1

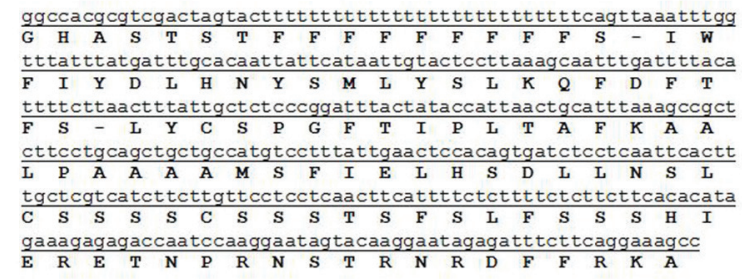

Figura 5. Secuencia aminoacídica obtenida a partir de la secuencia precursora de péptidos de Agalychnis spurrelli. Secuencia de 75 aminoácidos amplificada a partir de A.spuF1AUAP. La secuencia nucleotídica se encuentra subrayada.

de péptidos de la familia Hylidae, una propieza acídica que mantiene el extremo ArgininaLisina, y la región N-terminal de precursores de dermaseptinas (Vanhoye et al., 2003).

Mediante la comparación de las secuencias nucleotídicas y aminoacídicas de $A$. spurrelli con los secuencias presentes en el banco génico NCBI, se obtuvieron índices de identidad que nos indican que estos amplicones, y las secuencias aminoacídicas, poseen un alto grado de similaridad con secuencias ortólogas de A. annae.

La diversificación de los loci pudo haber sido parte de una estrategia evolutiva desarrollada por estas especies como resultado de cambios del nicho ecológico, tomando en cuenta el dramático cambio evolutivo de predadores microbianos (Duda et al., 2002). El uso de una familia de proteínas para realizar estudios evolutivos y de relaciones filogenéticas requiere de la identificación de miembros de esta familia con funciones similares en la gama más amplia posible de organismos. La información

Tabla 3. Índices de identidad de la secuencia aminoaminoacídica traducida a partir de A.spuF1-AUAP (3’RACE) de Agalychnis spurrelli comparados con las secuencias de sus ortólogos en otras especies

\begin{tabular}{ccc}
\hline Especie & Tipo De Secuencia & Identidad Máxima \\
\hline Agalychnis annae & mRNA for dermaseptine-related peptide, clone AA-3-1 & $58 \%$ \\
Phyllomedusa hypocondrialis & mRNA for dermaseptine H1 protein precursor (dsn-1 gene) & $45 \%$ \\
Agalychnis callydrias & Dermaseptine-like precursor DRP-AC-3 & $41 \%$ \\
Phyllomedusa hypocondrialis & mRNA for dermaseptin H2 protein precursor (dsn-2 gene) & $45 \%$ \\
Agalychnis callydrias & mRNA for DRP-AC-1 precursor & $41 \%$ \\
Phyllomedusa sauvagei & mRNA for preprodermaseptin S12 (drsS1 gene) & $44 \%$ \\
Phyllomedusa sauvagei & Partial mRNA for preprodermaseptin S13 (drsS1 gene) & $46 \%$ \\
Agalychnis callydrias & mRNA for ARP-AC-1 precursor & $43 \%$ \\
Agalychnis annae & mRNA for dermaseptine-related peptide, clone AA-3-3 & $38 \%$ \\
Agalychnis annae & mRNA for dermaseptine-related peptide, clone AA-3-4 & $30 \%$ \\
Agalychnis callidryas & mRNA for ARP-AC1 precursor & $90 \%$ \\
Phyllomedusa hypocondrialis & mRNA for phyllosepti-8 protein precursor & $86 \%$ \\
Phyllomedusa sauvagei & mRNA preprodermaseptin S9 (drsS9 gene) & $86 \%$ \\
\hline
\end{tabular}


extraída de la familia de proteínas puede usarse para el análisis de divergencia y relación evolutiva. Sin embargo, esta información debe ser comparada con investigaciones sobre fisiología y bioquímica de los organismos (Lehninger et al., 2008).

No obstante, la información obtenida a partir de la secuencia precursora de péptidos antimicrobianos de $A$. spurrelli ha servido, en este estudio, para la preliminar identificación de uno de los péptidos antimicrobianos presente en las secreciones de la piel de dicho organismo.

\section{CONCLUSIONES}

- La secuencia nucleotídica precursora de péptidos antimicrobianos presente en Agalychnis spurrelli, pertenece a los precursores de antimicrobianos de la subfamilia Phyllomedusinae, ya que fue amplificada con las regiones altamente conservadas características de este grupo taxonómico.

- Gracias al alto grado de conservación de las secuencias nucleotídicas precursoras de péptidos antimicrobianos de la subfamilia Phyllomedusinae, estas pudieron ser adecuadamente usadas como iniciadores para la caracterización molecular de péptidos antimicrobianos relacionados.

- La secuencia precursora de Agalychnis spurrelli posee un alto grado de identidad con su ortólogo en la especie Agalychnis annae, por lo cual puede inferirse una historia evolutiva muy cercana de estas especies por presiones de evolución adaptativa.

- La secuencia aminoacídica del péptido antimicrobiano obtenida de Agalychnis spurrelli y las de sus ortólogos Agalychnis annae, Agalychnis callidryas, Phyllomedusa hypochondrialis y Phyllomedusa sauvagei, posee una región altamente conservada, una propieza acídica que exhibe el extremo Arginina-Lisina, y una región C-terminal multivariable, regiones que son características de los precursores de dermaseptinas.

\section{AGRADECIMIENTOS}

Los autores expresan su imperecedero agradecimiento a la Dra. Iliana Alcocer Negrete del Laboratorio de Microbiología de la PUCE y a la Dra. Jeannete Zurita, de Zurita\&Zurita Laboratorios, por su incondicional apoyo. Al personal de los laboratorios de Microbiología, de Biología del Desarrollo y del Laboratorio de Investigaciones de
Citogenética y Biomoléculas de Anfibios (LICBA), de la Escuela de Ciencias Biológicas de la PUCE por su constante colaboración. A la Pontificia Universidad Católica del Ecuador por el apoyo financiero otorgado al proyecto: Caracterización química y citogenética de anfibios ecuatorianos.

\section{REFERENCIAS BIBLIOGRÁFICAS}

Amiche M, Ladram A, Nicolas P. 2008. A consistent nomenclature of antimicrobial peptides isolated from frogs of the subfamily Phyllomedusinae. Peptides, 247: 870-875.

Barra D, Simmaco M. 1995. Amphibian skin: A promising resource for antimicrobial peptides. Trends in Biotechnology, 13(6): 205-209.

Charpentier S, Amiche M, Mester J, Vouille V, Le Caer JP, Nicolas P, Delfour A. 1998. Structure, Synthesis, and Molecular Cloning of Dermaseptins B, a Family of Skin Peptide Antibiotics. The Journal of Biological Chemistry, 273(24): 14690-14697.

Chuang PH. 2012. Evaluación de la actividad anticancerígena del extracto peptídico crudo de Agalychis spurrelli. Tesis de Lienciatura en Ciencias Biológicas, Pontificia Universidad Católica del Ecuador, Quito, Ecuador.

Cilveti C, Rivera M, Rodríguez-Riglos M, Alcocer I. 2013. Inhibición de Enterobacterias Portadoras de Carbapenemasas con Secreciones Peptídicas de Anfibios Nativos Ecuatorianos. Revista Ecuatoriana de Medicina y Ciencias Biológicas, Volumen XXXIV(1,2): 85-98.

Coloma LA, Hoomoed MS, Quiguango-Ubillús A. 2011. Anfibios de Ecuador. Fundación Otonga. En línea <http/ / www.puce.edu.ec/Zoología/ anfecua.htm> Cons $\mu$ ltado: Marzo, 2012.

De Lucca A, Bland J, Jacks T, Grimm C, Walsh T. 1998. Fungicidal and binding properties of the natural peptides cecropin B and dermaseptin. Medical Mycology, 36:291-298.

Duda TF, Vanhoye D, Nicolas P. 2002. Roles of Diversifying Selection and Coordinated Evolution in the Evolution of the Amphibian Antimicrobial Peptides. Molecular Biology and Evolution, 19(6): 858-864.

Lehninger AL, Nelson DL, Cox M. 2008. Principles of Biochemistry. W.H. Freeman. New York, USA. 
Simmaco M, Mignogna G, Barra D. 1998. Antimicrobial Peptides from Amphibian Skin: What do they tell us? Biopolymers (Peptide Science), 47: 435-450.

Tennessen JA, Blouin MS. 2008. Balancing Selection at a Frog Antimicrobial Peptide Locus: Fluctuating Immune Effector Alleles? Molecular Biology and Evolution, 25: 2669-2680.

Vanhoye D, Bruston F, Nicolas P, Amiche M. 2003. Antimicrobial Peptides from Hylid and Ranin frogs originated from 150-million-year-old ancestral precursor with a conserved signal peptide but a hypermutable antimicrobial domain. European Journal of Biochimestry, 207:2068-2081.
Vargas A. 2012. Pruebas antimicrobianas de secreciones cutáneas de Agalychis spurrelli (Anura: Hylidae) en cinco especies de levaduras patógenas del género Candida. Tesis de Lienciatura en Ciencias Biológicas, Pontificia Universidad Católica del Ecuador, Quito, Ecuador.

Watson JD, Caudy AM, Myers RM, Wtkowski JA. 2007. Recombinant DNA. Genes and Genomes-a short course. pp. 85-87. W.H. Freeman and Company. 